\title{
CINEMA E EDUCAÇÃO AMBIENTAL: INTERLOCUÇÕES A PARTIR DE UM ESTUDO DE RECEPÇÃO DO FILME AVATAR
}

Rodrigo Avila Colla ${ }^{1}$

\section{RESUMO}

O presente artigo apresenta dados de uma pesquisa realizada em $2010 \mathrm{com}$ estudantes do $7^{\circ}, 8^{\circ}$ e $9^{\circ}$ ano do Ensino Fundamental. Na ocasião, foi aplicado um questionário junto a 76 sujeitos que abordava questões relativas à percepção de certos aspectos presentes no filme Avatar, de James Cameron. O trabalho se vale, principalmente, das contribuições teóricas de Humberto Maturana e Elizabeth Ellsworth. O primeiro ajuda a fundamentar a prática educativa em educação ambiental enquanto um processo voltado para a mudança de conduta numa perspectiva de sensibilização ambiental. A segunda contribui com a análise dos dados na medida em que aponta caminhos para um diálogo entre aspectos referentes ao endereçamento da película e sua recepção. Por fim, a partir da pesquisa realizada, sugere-se algumas abordagens para o uso pedagógico do filme.

Palavras-chave: Avatar; Cinema e Ambientalismo; Educação Ambiental; Educação e Cinema; Estudos de Recepção.

\section{CINEMA AND ENVIRONMENTAL EDUCATION: INTERLOCUTIONS FROM A RECEPTION STUDY OF THE MOVIE AVATAR}

\begin{abstract}
This article presents data from a research conducted in 2010 with 7th, 8th and 9th grade elementary school students. At the time, a questionnaire was applied to 76 subjects that addressed issues related to the perception of certain aspects present in James Cameron's film Avatar. The paper draws mainly on the theoretical contributions of Humberto Maturana and Elizabeth Ellsworth. The first helps to justify the educational practice in environmental education as a process aimed at changing behavior in a environmental awareness perspective. The second one contributes to the analysis of the data, insofar as it points the way to a dialogue between aspects regarding the addressing of the film and its reception. Finally, based on the research carried out, it is suggested some approaches for the pedagogical use of the film.
\end{abstract}

Keywords: Avatar; Cinema and Environmentalism; Environmental Education; Education and Cinema; Reception Studies.

\footnotetext{
1 Doutor em Educação pela PUCRS. Bacharel em Comunicação Social, habilitação em Relações Públicas, pela Universidade Federal do Rio Grande do Sul (UFRGS). E-mail: rodrigo.a.colla@gmail.com
} 


\section{INTRODUÇÃO}

Os jovens e adultos vêm se formando num mundo a cada dia mais impregnado por imagens em movimento. Por outro lado, há a preocupação crescente com a preservação do planeta, do ecossistema, e a recorrente pergunta: como afinal deveria ser nossa relação com o ambiente? Este artigo visa a apresentar dados de uma pesquisa realizada em 2010. Trata-se de um estudo de recepção do filme $\operatorname{Avatar}^{2}$ junto a estudantes do $7^{\circ}, 8^{\circ}$ e $9^{\circ}$ ano do Ensino Fundamental. O filme é uma produção estadunidense lançada em 2009 com direção e roteiro de James Cameron.

O filme é narrado a partir da perspectiva de Jake Sully (Sam Worthington), um ex-fuzileiro naval confinado a uma cadeira de rodas. Num futuro distante (2154) Jake viaja a Pandora, uma das luas do planeta Polifemo, onde a humanidade criou uma estação espacial com a finalidade de explorar um minério raro que pode salvar a Terra de uma grave crise de energia: o unobtanium. Não há oxigênio na atmosfera de Pandora e, para tornar viável a prospecção do minério, os humanos criam o Programa Avatar, que consiste na criação de corpos (avatares) obtidos a partir da hibridização do DNA humano com o DNA dos Na'vis - nativos humanóides que habitam Pandora. Assim, os seres humanos, ligados a supercomputadores que emulam uma vida consciente a bordo dos avatares, exploram a lua e estreitam os laços com os Na'vis para atingir o seu intento. Entretanto, para obterem o unobtanium, os humanos terão colocar abaixo "árvores-mães" que detém o conhecimento da floresta de Pandora e mantém o ecossistema do local em equilíbrio (AVATAR, 2009).

Outros aspectos referentes ao enredo da película virão à tona ao longo do texto, mas, por ora, essa contextualização é suficiente. Obviamente, este trabalho não dará conta de abordar todas as possibilidades de problematizações de cunho ecológico que o filme apresenta, mas trará à tona

\footnotetext{
${ }^{2}$ A título de curiosidade, na época do lançamento do filme houve boatos de que ele seria o maior orçamento da história do cinema, tendo custado cerca de U\$500 milhões. Posteriormente, a Twentieth Century Fox Film Corporation, estúdio responsável pela produção, divulgou dados oficiais afirmando que o filme custou U\$237 milhões. Ainda assim, à época, tratava-se da terceira produção mais cara da história da sétima arte.
} 
alguns possíveis temas e confrontos entre perspectivas/percepções que podem balizar debates em atividades que fizerem uso pedagógico da película. A proposta desses quesitos é realizada com base em relatos dos estudantes que responderam aos questionários. Mais especificamente, algumas das sugestões são feitas a fim de suprir lacunas em suas respostas e argumentações que se devem à limitação do próprio método, a saber: o uso de questionários. A partir da exploração mais aprofundada da percepção dos estudantes por meio do diálogo mediado pelo(a) professor(a), acredita-se ser possível conduzir a um compartilhamento de olhares/emoções em prol da sensibilização ambiental.

O principal aspecto que motivou essa pesquisa foi o contexto - que nitidamente tem como dois pontos fundamentais de sua complexidade duas relações estabelecidas pelos sujeitos: com os meios audiovisuais e com o meio ambiente. Este trabalho, resumidamente, propõe a utilização do cinema em práticas pedagógicas voltadas para educação ambiental, a partir de um estudo do filme Avatar.

Por outro lado, a direção na qual a proposta será sugerida passa por um trânsito crítico e autocrítico pelos "entre-lugares" situados entre o endereçamento da película (a quem o filme pretende se dirigir) e as respostas a esse endereçamento (os múltiplos olhares, opiniões e entendimentos do filme no entrelaçamento com as variadas experiências pessoais dos educandos) (ELLSWORTH, 2001).

O objetivo principal da pesquisa é apontar possíveis caminhos para a abordagem de conceitos relacionados ao meio ambiente que poderiam ser trabalhados a partir do filme, tendo como ponto de partida o estudo de recepção da película. Isso se desenvolveria alicerçado numa dinâmica de educação ambiental que parta da sensibilização ambiental e propicie o diálogo e a valorização das múltiplas experiências dos educandos.

\section{DO MÉTODO}

Para o levantamento dos dados empíricos, foi elabora um questionário de modo que somente as pessoas que viram o filme estivessem aptas a responder às questões. De um total de 134 sujeitos pesquisados, 76 deles haviam visto o filme (56,7\%). Destes, 40 são do sexo masculino e 36 do sexo feminino. Os questionários foram aplicados em duas escolas da rede estadual 
de ensino localizadas em Porto Alegre - RS. A análise dos dados é feito por meio de um diálogo entre aspectos referentes ao endereçamento (ELLSWORTH, 2001) da película que, nitidamente, dialoga com indivíduos de seu tempo sem, contudo, deixar de sustentar certas marcas típicas de um filme hollywoodiano, trazendo também alegorias e opções de enredo que remetem a abordagens teóricas que nos aproximam de uma leitura ecológica do filme. Desse modo, é possível apontar certas possibilidades para seu uso na educação ambiental.

\section{DADOS OBTIDOS E ALGUMAS CONSIDERAÇÕES SOBRE O USO PEDAGÓGICO DO CINEMA}

Quando indagados sobre o personagem do qual mais gostaram, 65\% dos sujeitos afirmaram se identificarem mais com o protagonista, Jake Sully. Ao justificarem o porquê da identificação, muitos admitiram terem preferido o protagonista por ele ter sido o salvador de Pandora, por ter vencido o mal, por corajosamente ter se voltado contra os seus (os humanos), em prol de uma causa que lhe parecia justa, o bem. Nessa perspectiva, o maniqueísmo comumente explorado no cinema hollywoodiano, em Avatar aparece como:

- Espécie Humana (humanidade): o mal; o predador; o inimigo da ordem natural de Pandora. O motivo da sua cobiça: a energia, a tecnologia.

- Os Na'vis (navidade): o bem; a caça; os oprimidos que objetivam a manutenção do equilíbrio de seu habitat natural. A razão pela qual lutam: Pandora, a natureza;

Outra pergunta que foi feita no questionário, é a respeito do tema que mais teve destaque no filme. As opções eram: tecnologia, crise energética, romance dos protagonistas, preservação da natureza, guerra e outros. A distribuição das respostas foi a seguinte: $45 \%$ acreditam que a temática principal é o meio ambiente, 36\% elegeram a tecnologia, $11 \%$ a guerra, $4 \%$ a crise energética e $4 \%$ o romance entre os protagonistas. As razões pelas quais os estudantes optaram por esses temas acabaram não sendo bem explicitadas nos questionários, mas talvez pudesse ser um questionamento possível numa prática pedagógica com a utilização do filme. A questão da identificação, seja com um personagem, seja com uma cena ou temática é permeada por 
aspectos da ontogenia de cada sujeito. Aquilo que sensibiliza e, logo, suscita certa identificação é passível de ser problematizado, neste caso, no que diz respeito à perspectiva ambiental. Como provoca Ellsworth (2001, p. 12): "qual a relação entre o lado de 'fora' da sociedade [por vezes expressa nos filmes] e o lado de 'dentro' da psique humana [podendo ser entendida como parte da ontogenia de cada indivíduo]?". Uma obra cinematográfica é um recurso bastante potente para trabalhar essa relação.

Outra questão abordada no questionário foi um fato menos comum nos filmes: numa guerra contra extraterrestres, os humanos são os vilões. A esse respeito, $50 \%$ dos estudantes admitiram sentirem alguma forma de estranhamento. Alguns confessaram sentirem vergonha, outros raiva ou repulsa. Alguns atribuíram o fato de não sentirem tal estranhamento à crença de que o ser humano é repleto de maldade, outros justificaram com 0 argumento de que se trata apenas de uma obra de ficção. Houve ainda outros estranhamentos: a paixão de um humano por uma fêmea de outra espécie por um modo de vida tão distinto do seu. Hipóteses levantadas pelos estudantes para justificar essa escolha do personagem no enredo foram: o fato de, vivendo no avatar, ele ter conquistado novamente a capacidade de andar, uma vez que era paraplégico, e ter sido seduzido pela liderança que acabou exercendo. Além disso, foi elencada a hipótese de Jake ter se deslumbrado com o poder da natureza de Pandora e, sobretudo, com os recursos a habilidade que os na'vis possuíam para interagir com ela de modo a obter benefícios.

Tais estranhamentos ou suas ausências poderiam, por exemplo, ser confrontados com as temáticas elencadas pelos alunos a fim de compreender os modos como percebem as relações humanas com 0 ambiente. Particularmente no caso do uso da película como dispositivo problematizador, esse processo pode ser favorecido. Tratar-se-ia de uma investida no sentido de entender como se constitui o imaginário dos educandos no que diz respeito ao meio ambiente. Afinal, o desafio tanto de pesquisadores quanto de professores, no que tange ao uso pedagógico do cinema, tem sido "entender o modo como as relações entre mídia audiovisual e sociedade interferem na composição do imaginário social, na produção de identidades e na transmissão de valores éticos e morais" (DUARTE, 2002, p. 64). 
Aqui, embora as relações mencionadas por Duarte (2002) também estejam presentes, discute-se imaginário social no que toca um aspecto pontual. Poder-se-ia dizer que se vislumbra o imaginário social-ambiental. 0 uso pedagógico dos filmes pode contribuir com a aproximação desse horizonte. Isso porque, evidentemente, é mais fácil para um sujeito revelar identificação/estranhamento com cenas/temáticas do que confessar certas atitudes passíveis de repreensão. Nesse sentido, caberia ao educador se valer do próprio filme enquanto recurso estético e potencialmente sensibilizador e de propostas de debate sobre ele para averiguar disposições de atitudes em relação ao meio e poder intervir, recorrendo também à teoria, mediando um processo de reformulação de condutas e valores. Para tanto, é interessante que se crie um ambiente favorável a uma dinâmica de emoções de aceitação e diálogo. O próprio uso do cinema em parte já contribui com uma atmosfera propícia para esse tipo de sentimento. Ora, como sustenta Alain Badiou (2004), o cinema é um meio que nos defronta com o outro e nos ajuda a refletir a complexidade de suas relações com o mundo. Nesse viés, o uso pedagógico do cinema é passível de potenciar o pensamento da alteridade e ampliar nossa visão sobre a diferença (BADIOU, 2004).

O filme, como se pode notar, produz sensações bastante diversas, mas dialoga com as preocupações do seu tempo e tem intenções claras de endereçamento. Mesmo sendo visto por pessoas pertencentes a um mesmo contexto e num mesmo momento histórico, suscita distintas formas de se relacionar com ele, pois "não existe nenhum ajuste exato entre endereço e resposta (ELLSWORTH, 2001, p. 13)”. Além disso, e creio que aqui resida o principal argumento que sustenta o uso de uma pedagogia audiovisual, "[...] o evento do endereçamento ocorre num espaço que é social, psíquico, ou ambos, entre o texto do filme e os usos que o espectador faz dele (ELLSWORTH, 2001, p. 13)". Estes, contudo, podem ser mediados em debates em sala de aula e enriquecidos por visões e sensações bastante heterogêneas. O potencial sensibilizador do cinema, aqui no que diz respeito à sensibilização ambiental, também passa pela potência que as obras cinematográficas encerram enquanto dispositivos disparadores do debate e propiciadores de repertório estético/cenográfico.

Embora Avatar se insira no grande gênero cinematográfico "ficção" e, 
dentro desse gênero, seja classificado como um filme de "ficção científica", cabe salientar, com Rancière (2005, p. 58), que "o real precisa ser ficcionado para ser pensando".

\section{CINEMA E EDUCAÇÃO AMBIENTAL: DIÁLOGOS E APROXIMAÇÕES A PARTIR DA PESQUISA COM O FILME AVATAR}

$\mathrm{Na}$ hipótese aqui defendida, a valorização das experiências dos educandos em sala de aula e, posteriormente, o estímulo para que elas inspirem uma atividade prática de produção audiovisual-ambiental, por exemplo, consistiria no alicerce de uma dinâmica de sensibilização ambiental que, por sua vez, subjazeria a uma tomada de consciência gradativa e poderia propiciar o reconhecimento da responsabilidade individual de cada educando em sua conduta em relação à natureza. O cinema constitui um recurso interessante tanto como dispositivo disparador para o diálogo e para a reflexão quanto na busca por propiciar experiências estéticas e passíveis de sensibilização.

Nesse sentido, é pertinente citar Maturana (2004). Na visão do autor, "a responsabilidade ocorre quando se está consciente das consequências das próprias ações e quando se age aceitando-as. Isso inevitavelmente acontece quando uma pessoa se reconhece como parte intrínseca do mundo em que vive" (MATURANA, 2004, p. 47).

Levando em conta o potencial estético do cinema, entendemos que esse tipo específico de narrativa audiovisual pode propiciar uma sensibilização que sirva de alicerce para transformações das dinâmicas de saberes-fazeres dos educandos, em suas interações com o meio. Tais transformações dar-se-iam pela assunção do "outro" (no caso, o meio) enquanto legítimo outro na convivência (MATURANA, 1998) e passariam pelo reconhecimento de sua responsabilidade no histórico de interações.

Se, como sustenta Maturana (1998), nossos saberes e a própria linguagem estão fundados em emoções, paralelamente, este trabalho preconiza a problematização do que parece claro para muitos, de acordo com as respostas dos questionários: os meios pelos quais o filme defende a preservação da natureza. Isso poderia gerar reflexões intermediadas por 
experiências de cunho estético e, assim, fundar uma verdadeira racionalidade ambiental, pois, para Morin (2007, p. 23), a racionalidade "deve reconhecer a parte de afeto, de amor e de arrependimento", em outras palavras, a racionalidade não é só razão, mas também emoção.

Diagnosticando um aspecto de sua ontogenia que lhes leva a sentir identificação com determinada cena, os estudantes, levando em conta que esses históricos de interações com o meio sempre ocasionarão mudanças, poderão estar percorrendo o início do caminho para reconhecer sua responsabilidade no universo de ações humanas que constituem condutas perniciosas para a natureza. Evidentemente, isso não se daria de forma tão simples e causal, pois teria de haver o intermédio do educador no sentido de tornar clara essa influência individual de cada educando no meio ambiente em que está inserido e, mais do que isso, a influência do meio na formação de cada um. Em outras palavras, seja qual for a noção que o sujeito possui de sua relação com o meio, do seu domínio de condutas, do estado em que o ambiente se encontra, indivíduo e meio estarão mutuamente se formando, se remodelando, num eterno diálogo que modifica as duas partes. Essa adequação recíproca do meio em relação ao indivíduo e do individuo em relação ao meio é o que Maturana e Varela (2001) chamam de acoplamento estrutural.

Porém, aqui, o cinema é outro elemento que entra nessa relação. Não cabe aqui discutirmos o teor artístico ou não da película em análise, mas, de qualquer modo, podemos tecer algumas considerações sobre seu caráter dinâmico e estético. Para João-Francisco Duarte Júnior (1988, p. 43),

A arte é sempre a criação de uma forma. Toda arte se dá através de
formas, sejam elas estáticas ou dinâmicas. Como exemplo de formas
estáticas temos: o desenho, a pintura, a escultura, etc. E como
exemplo de dinâmicas: a dança (o corpo descreve formas no
espaço), a música (as notas compõem formas sonoras), o cinema,
etc. Nas artes "dinâmicas" as formas se desenvolvem no tempo, ao
contrário das artes "estáticas" cujas formas não variam
temporalmente.

Considerando que a ontogenia é um processo dinâmico, ininterrupto, sistêmico, quiçá nada mais condizente para reproduzir a lógica desse processo do que nos utilizarmos de uma pedagogia orientada por uma arte dinâmica. $O$ desenvolvimento das formas no tempo é, afinal, semelhante ao que ocorre no 
histórico de interações dos sujeitos em suas relações com o meio.

O reconhecimento por parte do sujeito de sua responsabilidade o insere num domínio de comportamento que Maturana (1998) chama de "objetividade entre parêntese". Quando um sujeito está envolvido por emoções que fazem com que se mova nessa dinâmica comportamental, considera seu papel atuante em tudo aquilo que pensa e faz, ou seja, nada é completamente abstrato ou isolado de sua influência, mas fundado em alguma espécie de emoção que motiva uma disposição do indivíduo. Nesse domínio, o sujeito não atribui de modo causal e determinista as suas argumentações a fatores externos, mas se coloca como parte integrante de suas justificativas e atos. Faz-se imprescindível, portanto, criar possibilidades para que se constitua uma dinâmica de emoções propícias para a aceitação (do outro e de si) e que, consequentemente, integre a subjetividade.

Por outro lado, citando outro exemplo que corrobora e aprofunda essa ideia, na medida em que o sujeito integra seu meio (e ao mesmo tempo nele se reconhece como integrante e atuante) em suas argumentações reconhecendo sua responsabilidade na dinâmica de condutas estabelecidas para com ele e a interdependência das relações ecológicas, desenvolve outra relação de pertencimento. "Nossa civilizada desconfiança dos sentidos e do corpo engendra um deslocamento metafísico do mundo sensível", escrevem Carvalho e Steil (2009, p. 88) apoiados em Abram. Na visão dos autores, "isso alimenta a ilusão de que nós mesmos não fazemos parte do mundo que estudamos, do qual podemos nos manter a parte, como espectadores, e assim determinar seu funcionamento desde fora" (CARVALHO; STEIL, 2009, p. 88). As emoções que promovem essa cisão desintegradora são muito semelhantes àquelas que fundam racionalidades que eximem os sujeitos da responsabilidade pela natureza das relações a que se referem. Trata-se do mesmo corpo que sente e percebe o mundo e que, nessas ocasiões, quer "tirar o corpo fora", isto é, livrarse do risco de poder ser responsabilizado em situações delicadas. Responsabilidade, aliás, na visão de Hans Jonas (1995, p. 357, grifo do autor, tradução nossa).

é o cuidado, reconhecido como dever, por outro ser, cuidado que, dada a ameaça de sua vulnerabilidade, se converte em 
'preocupação'. Não obstante, o temor está já como potencial na pergunta originária com a que se pode representar inicialmente toda responsabilidade ativa; $O$ quê sucederá a isso se dele eu não me ocupar?

Dando especial atenção ao esclarecimento do temor enquanto agente da responsabilidade, Jonas (1995) faz questão de desvinculá-lo da noção de fraqueza ou covardia, o imputando um caráter de maturidade e lucidez:

\begin{abstract}
Nós por nossa parte não tememos em absoluto que nos acusassem de pusilanimidade ou negatividade ao declarar que o temor é um dever, que, naturalmente, só pode ser acompanhado da esperança (da esperança de poder prescindi-lo): temor fundado, não intimidação; quiçá medo, mas não angústia; e em nenhum caso temor ou medo por si mesmos. Evitar o medo onde corresponde tê-lo seria angústia (JONAS, 1995, p. 358, tradução nossa).
\end{abstract}

O temor estaria assim habilitado para fundar o respeito e, nele, o horizonte da responsabilidade. A angústia, por outro lado, só poderia provocar a atribulação e a incapacidade de agir lucidamente.

Jonas (1995), como Maturana (1998), fundamenta seus argumentos éticos em emoções. O cinema, arte mobilizadora de emoções de uma ampla gama de tipos de sujeitos, parece representar um recurso bastante rico para potenciar experiências pedagógicas em que pressupostos éticos entram em jogo. E este é o caso das práticas levadas a cabo na educação ambiental.

\title{
CONSIDERAÇÕES FINAIS
}

Com o crescente dinamismo na difusão de informação e a multiplicação explosiva dos meios pelos quais é propalada, a geração Google, como optarei chamá-la aqui, tem promovido mudanças radicais nas formas de relação alunoescola. O lépido contexto em que estão inseridos, de alguma forma, contrasta com a fixidez metodológica de certas práticas educativas tradicionais. Isso ocasiona uma perda de credibilidade da instituição escolar junto ao público a que atende e à sociedade em geral. Os jovens de hoje muitas vezes não utilizam mais o verbo "escrever", mas "digitar", os termos usados são: linkar, blogar, twittar, etc. $\mathrm{Na}$ era digital, tudo é tão célere que os professores do Ensino Básico, para os educandos, tornaram-se praticamente "dinossauros". Afinal, de que servem professores se, na dúvida, há o Google, na crise criativa, lá também há trabalhos escolares prontos ou pré-prontos. Há quem se 
medique pelo site de busca: é só escrever os sintomas e eis o remédio. O fato é que o Google, para tudo (ou quase tudo), virou remédio. Mas o quê o site tem a ver com a proposta deste trabalho?

Em tempos em que o bullying tornou-se largamente discutido na educação e ganhou as capas de jornais, as dividiu com Avatar, aliás, quiçá recorrer a métodos mais dinâmicos e interativos seja um remédio profícuo. Assim, lançar mão de bens culturais que se tornaram marcos da cultura popular - os campeões de procura no Google em suas épocas - pode ser uma medida bastante conveniente para despertar o interesse dos alunos. Para fazer isso bem-feito, evidentemente, é requerido o reconhecimento do caráter interdisciplinar como aliado nesse processo. As disciplinas não precisam valerse de programas estanques, com conteúdos e saberes que parecem não possuir qualquer relação entre si; pelo contrário, os diferentes saberes e as diferentes pedagogias podem dialogar a partir de um dispositivo que esteja a serviço da educação ambiental. Nessa perspectiva, a necessidade de se educar ambientalmente e a conveniência da utilização do cinema na educação e, mais do que isso, esses dois aspectos cooptados podem, além de mutuamente se fortalecerem, serem facilitadores do viés sistêmico na educação.

Restringindo-nos ao caso do uso pedagógico de uma obra cinematográfica, para que se proponha uma atividade que mobilize abordagens e conhecimentos realmente significativos para os educandos, é interessante levar em conta: a(s) abordagem(ns) temática(s) do filme, sua forma de inserção no contexto sóciocultural, as técnicas cinematográficas utilizadas, a trilha sonora, noções de semiótica, alguns conhecimentos básicos de análise de discurso, entre outros aspectos. Em contrapartida, numa perspectiva interdisciplinar, o filme tanto pode ser objeto de discussão da física quanto da biologia, ou, como na proposta aqui defendida, ser utilizado como recurso fomentador de problematizações sobre a educação ambiental. 


\section{REFERÊNCIAS}

AVATAR. Direção: James Cameron, Produção: James Cameron e Jon Landau. Estados Unidos; Reino Unido: Twentieth Century Fox Film Corporation, Dune Entertainment, Ingenious Film Partners e Lightstorm Entertainment, 2009.

BADIOU, Alain. El Cine Como Experimentación Filosófica. In: YOEL, Gerardo (Comp.). Pensar el Cine 1 - Imagen, ética y filosofia. Buenos Aires: Manantial, 2004, p. 23-81.

CARVALHO, Isabel Cristina de Moura; STEIL, Carlos Alberto. "O Habitus Ecológico e a Educação da Percepção: fundamentos antropológicos para a educação ambiental”. Educação \& Realidade. Porto Alegre, v. 34, n. 3, set/dez 2009.

DUARTE, Rosália. Cinema \& Educação. Belo Horizonte: Autêntica, 2002.

DUARTE JÚNIOR, João-Francisco. Por que arte-educação? Campinas: Papirus, 1988.

ELLSWORTH, Elizabeth. Modos de Endereçamento: uma coisa de cinema, uma coisa de educação também. In: SILVA, Tomaz Tadeu (Org.). Nunca Fomos Humanos: nos rastros do sujeito. Belo Horizonte: Autêntica, 2001.

JONAS, Hans. El Princípio de Responsabilidad: ensayo de una ética para la civilización tecnológica. Barcelona: Editorial Herder, 1995.

MATURANA, Humberto. Emoções e Linguagem na Educação e na Política. Belo Horizonte: Ed. da UFMG, 1998.

MATURANA, Humberto; VARELA, Francisco. A Árvore do Conhecimento: as bases

biológicas da compreensão humana. São Paulo: Palas Athena, 2001.

MATURANA, Humberto R. Conversações Matrísticas e Patriarcais. In: MATURANA, Humberto R.; VERDEN-ZÖLLER, Gerda. Amar e Brincar: fundamentos esquecidos do humano do patriarcado à democracia. São Paulo: Palas Athena, 2004.

MORIN, Edgar. Os Sete Saberes Necessários à Educação do Futuro. Brasília: UNESCO, 2007.

RANCIÈRE, Jacques. A Partilha do Sensível. São Paulo: Editora 34, 2005. 